\title{
Robot-Assisted Ultraviolet Disinfector with Dispenser for Healthcare Related Services
}

\author{
Shatrughna Prasad Yadav, Sai Kumar, Boddu Devika, and Kolluri Rahul
}

\begin{abstract}
Recently healthcare sector has attracted service robots to prevent the spread of infection. During COVID-19 pandemic, service robots have been able to reduce direct contact of front-line healthcare workers by separating them from direct exposure to infection. Robots have been used for delivery systems, disinfection of the exposed area, remote monitoring of patients, etc. In the present work, we have designed a disinfection robot that radiates ultraviolet $C$ rays for $U V$ sterilization of hospitals that kills $95.0 \%$ of bacteria within 20 second of exposure from a distance of 0.5 meter. UVC disinfection is more effective than disinfection by hydrogen peroxide, and with other chemical-based disinfectants like chlorine, chloramine, etc. Our designed robot can also be used as a dispenser in hospital delivery system for transporting medicine, laboratory samples, etc. Its use will not only increase logistics efficiency but will also avoid spread of Hospital Acquired Infections (HAIs), healthcare associated infections, eliminate human error, and allow health workers to engage themselves in their higher priority works.
\end{abstract}

Keywords - Disinfection robot, Dispenser Robot, Healthcare Associated Infection, Hospital Acquired Infection, Ultraviolet light.

\section{INTRODUCTION}

Healthcare associated infections are growing rapidly and has become more apparent in the present time due to COVID19 pandemic. The infections caused is growing and is a very serious problem for the healthcare sector. It has given rise to significant cost due to large number of infected patients, prolonged stay in bed, readmissions, and unprecedented deaths due to outbreak of pandemic. This has put severe social, economic, and clinical burden not only in the society but also on healthcare sectors [1]. The major source of infection may be other patients, equipment, healthcare staff, visitors and even the environments [2].

Robots can be used in the hospitals for variety of automated services including disinfection of the exposed area, delivery of medicines and remote monitoring of patients, etc. Its use will reduce direct contact of front-line hospital workers by separating them from direct exposure to infection [3].

In this paper we have designed a robot for disinfection of the exposed area using Ultraviolet Germicidal Irradiation (UVGI). The Robot can be also used for delivery of

Submitted on December 16, 2021

Published on January 10, 2022.

Shatrughna Prasad Yadav, Electronics and Communication Engineering Department, Guru Nanak Institute of Technology, Hyderabad India. (e-mail: spyadav68@ gmail.com)

Sai Kumar, Electronics and Communication Engineering Department, Guru Nanak Institute of Technology, Hyderabad India.

(e-mail: chsaikumarcsk312@gmail.com) medicines, blood samples etc. While functioning as a UV-C disinfector, it uses ultraviolet rays type C (UV-C) in $220 \mathrm{~nm}$ to $280 \mathrm{~nm}$ wavelength to inactivate or kill germs either by disrupting their DNA or by destroying nucleic. The UV-C radiation would kill or inactivate microorganisms and unable them to perform their vital cellular functions [4]. Use of UV$\mathrm{C}$ irradiation has many advantages that include simple to operate, low cost and labor incentive, lack of harmful residuals, effective against broad-spectrum organisms, and contactless operation etc. [5].

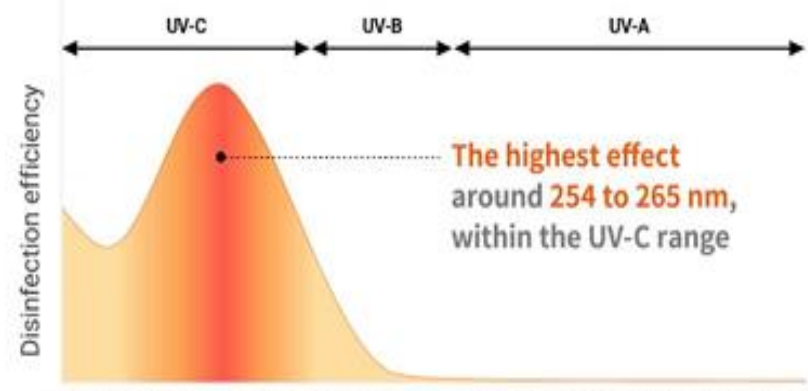

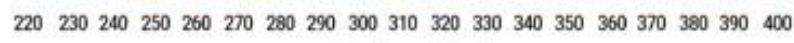
Wavelength $(\mathrm{nm})$

Fig. 1. UV-C Disinfection Efficiency.

Ultraviolet spectrum is divided into three sub regions called UV-A, UV-B and UV-C as depicted in Fig. 1. Among the available three types, UV-C is more effective in destroying the bacteria mainly in the range of 254-265 nm wavelength. An alternative to UV-C is the use of far UV-C that emits lower wavelength in the range of 207-222 nm, but its use is at infancy stage and several studies are under progress to verify its effectiveness and challenges for safe uses [6].

Our designed robot can also be used as autonomous dispenser for delivery of medicine, medical supplies, laboratory samples, etc. [7]. This autonomous dispenser will prevent exposure of front-line hospital staff from the risk of getting affected with the virus apart from improving efficiency of delivery [8]. Approximately $30 \%$ time of hospital nurses are wasted away from patients due to their engagement in logistics support. In order to mitigate the risk of spreading disease by minimizing person to person contact,

Boddu Devika, Electronics and Communication Engineering Department, Guru Nanak Institute of Technology, Hyderabad India.

(e-mail: boddudevika2929@ gmail.com).

Kolluri Rahul, Electronics and Communication Engineering Department, Guru Nanak Institute of Technology, Hyderabad India.

(e-mail: kollurirahu19@gmail.com) 
our autonomous dispenser robot will prove to be a boon in the healthcare delivery system [9].

\section{DEVICES USED IN THE PRESENT WORK}

\section{A. Arduino UNO Development Board}

Arduino UNO as shown in Fig. 2 is a widely used Internet of Things (IoT) development board which is having 20 pins among them 6 pins are for analog input and 14 pins are for digital input/output [10]. It is an open-source microcontroller board based on ATmega328P. It operates with 5V DC power with current per I/O pin of around $40 \mathrm{~mA}$.

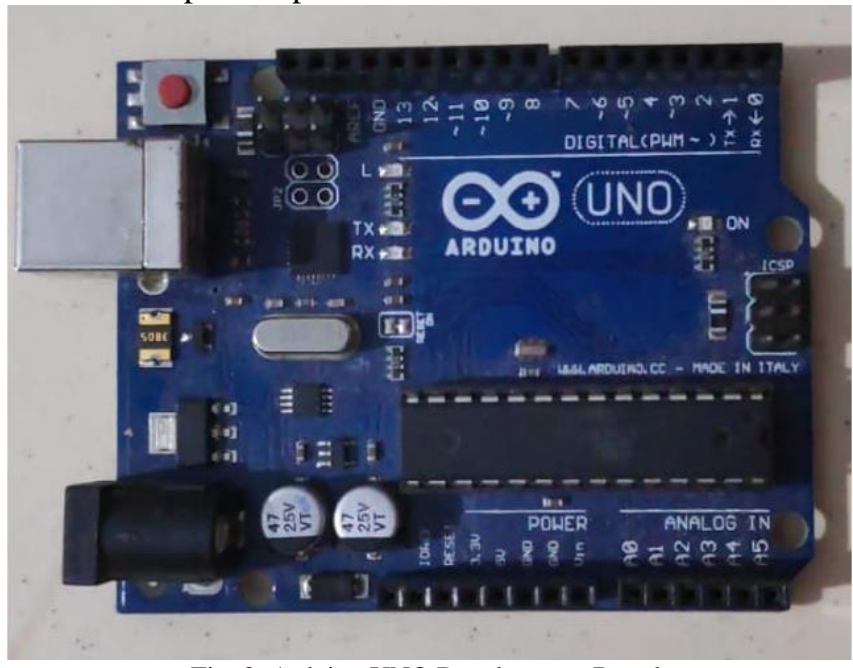

Fig. 2. Arduino UNO Development Board.

Arduino works with the software Arduino IDE (integrated development environment), that is to be installed in either personal computer/laptop before it is to be used for the given application [11].

\section{B. Motor Driver IC}

Fig. 3 shows the L298D, dual-H-bridge motor driver that is generally used to control the rotation of motors in clockwise as well in anti-clock wise direction. It is a highpower motor driver perfect for driving DC motors [12]. Its important features include operating voltage up to 40 Volts, provides current up to $3 \mathrm{amps}$, and able to drive four-phase stepper motors.

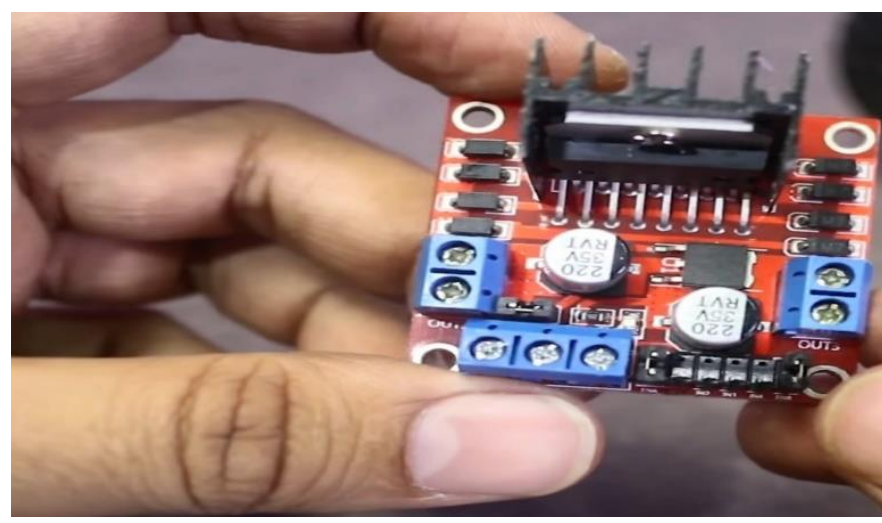

Fig. 3. Dual-H-Bridge Motor Driver.

Generally, motors require a high driving current in terms of ampere whereas controller can deliver current signals only in mille ampere. Motor driver is an amplifier which converts a low input current in high output current to drive the external load. [13].

\section{Wireless Bluetooth Module}

HC-05 depicted in Fig. 4 is a popular and widely used Bluetooth module that can be used in both in master as well as slave configurations. It has been designed for wireless communication applications [14]. It communicates with microcontroller using serial port (USART) at 9600, 19200, 38400, and 57600 baud rates. This Bluetooth module can be easily interfaced with Arduino UNO board as it supports USART port [15].

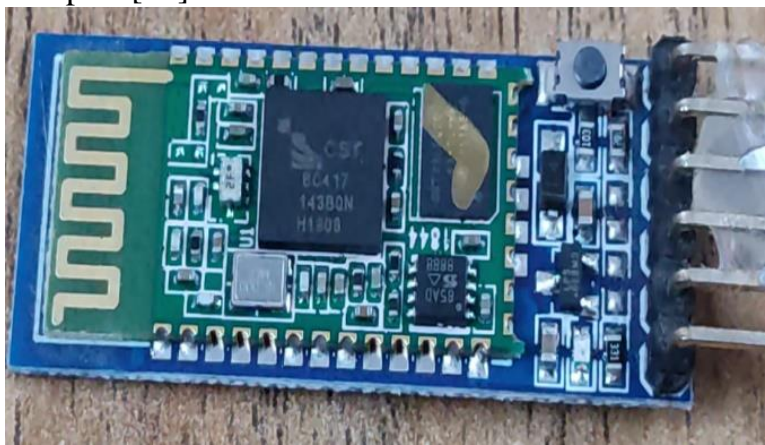

Fig. 4. Wireless Bluetooth module.

It is simple to pair it with microcontrollers as it operates using serial communication.

\section{My Robolab Robot}

My Robolab Robot is a mobile based application for Bluetooth interface with Arduino board. Its application includes sending and receiving of data with the help of Bluetooth connectivity [16]. It has a configurable keypad for sending specific data. It must be paired with smartphone and is to be interfaced with my robolab robot. After establishing the connectivity, it must send signals for movement of robot, like: $\mathrm{R}$ - for right turn, $\mathrm{L}$ - for left turn, $\mathrm{B}$ - for backward, $\mathrm{F}$ - to go front and $\mathrm{S}$ - to stop, etc.

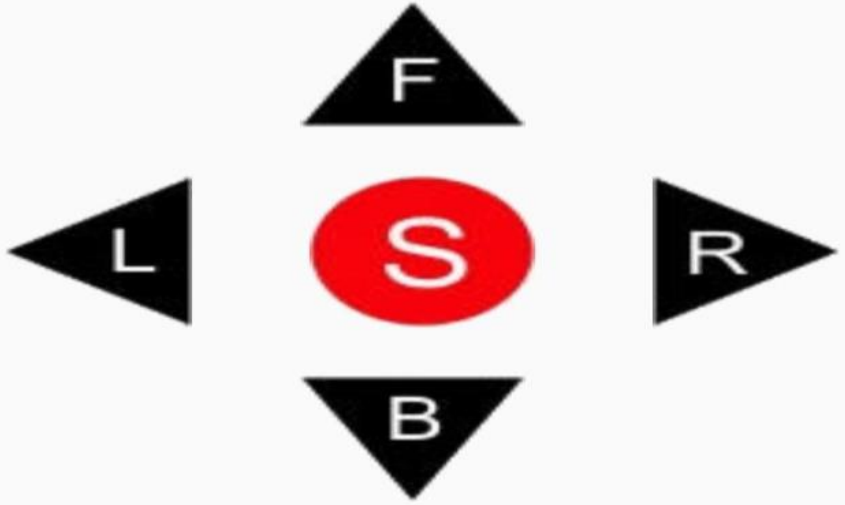

Fig. 5. My Robolab Robot.

\section{E. Ultraviolet Light Emitting Diodes}

Ultraviolet Light Emitting Diodes (UV LEDs) as shown in Fig. 6 are a low power, small size, echo friendly, short turnon time emerging UV source for disinfection [17]. It provides flexibility of design and are effective for disinfection of a large variety of pathogens. But it has the disadvantage of narrow emission spectra, and low output power as compared with UV lamps [18]. 


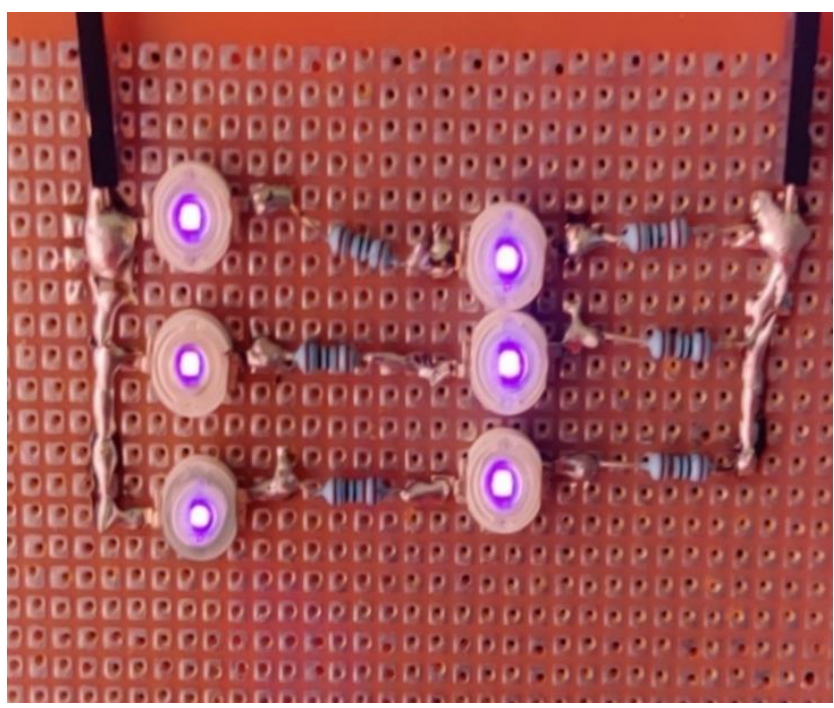

Fig. 6. UV-C LED

Ultraviolet (UV) spectrum as depicted in Fig. 7 lies between $\mathrm{x}$-ray and visible light on the electromagnetic spectrum [19]. UV-C LEDs are used extensively as germicidal irradiation (UVGI) for non-porous surface, and for air and water purification. UV-C photons damage the nucleic acid after entering the cells. We have used ZEU110BEAE-265 UV-C LED that consumes $50 \mathrm{~mW}$ of power, radiates $265 \mathrm{~nm}$ wavelength, operates with 5 volt of input power supply, and consumes $440 \mathrm{~mA}$ of current. Its half intensity angle is 120 degree, and its size is of $3.5 \times 3.5 \times 2.24$ $\mathrm{mm}$.

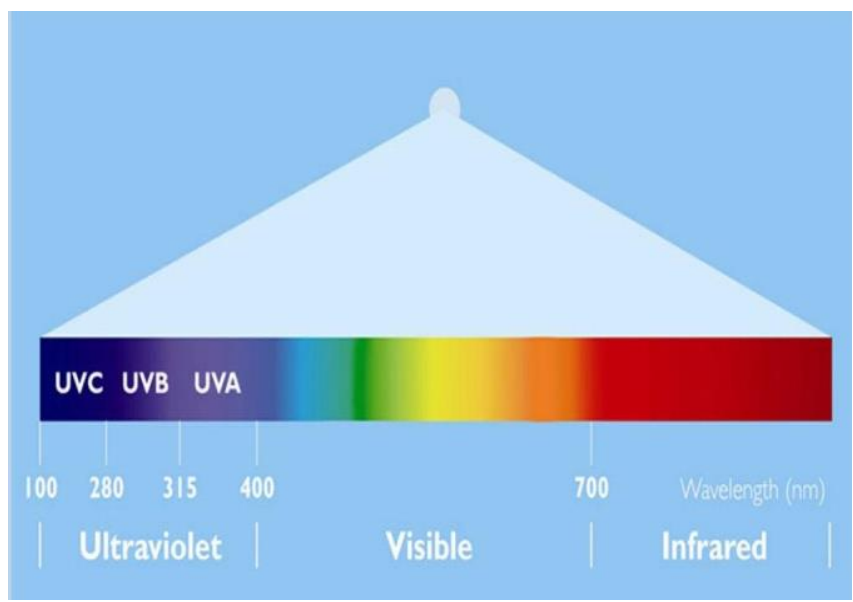

Fig. 7. UV Wavelength on Electromagnetic Spectrum.

\section{F. Servo Motor}

Fig. 8 shows Servomotor that has been used in our design for controlling of linear or angular position, acceleration, and velocity of the robot with the help of servomechanism. Movement of robot either for disinfection or for dispenser work is being controlled by this servo motor [20]. Its threepin configuration as shown in figure is used to connect brown wire to negative and red to positive power supply whereas orange wire has been used to connect pulse width modulation (PWM) signal [21].

\section{ARCHITECTURE OF THE PROPOSED SYSTEM}

Fig. 9 depicts the schematic diagram of our automated

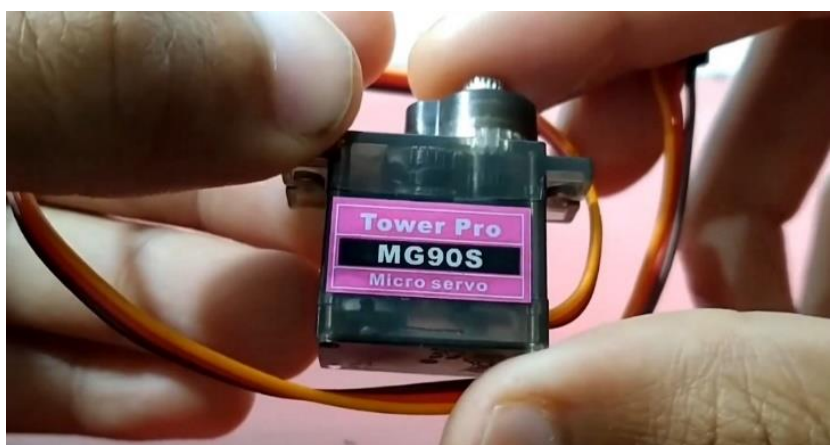

robot. The Arduino board has been interfaced with Bluetooth model, motor driver, UV-C LEDs, power supply etc. as depicted in figure.

Fig. 8. Servo Motor.

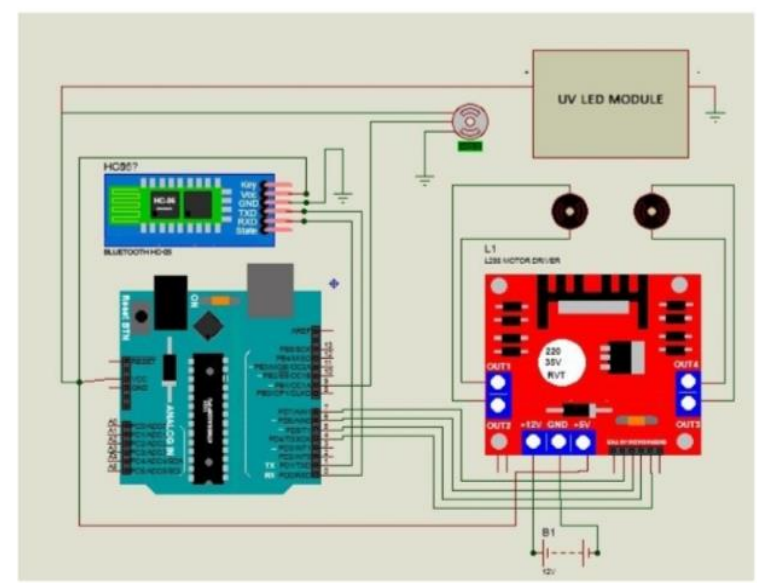

Fig. 9. Schematic Connection Diagram.

The data transmission block diagram is shown in Fig. 10. Path of data flow is from robot controller to Bluetooth module.

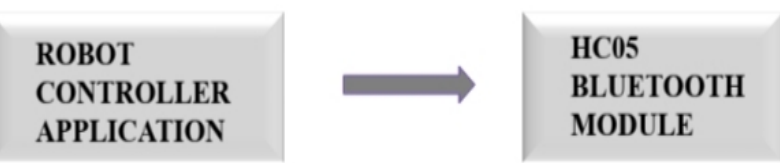

Fig. 10. Data Transmission Block Diagram.

Fig. 11 depicts the data flow path in the receiver module. The movement of robot is being controlled through My Robolab Robot that is a mobile based application for Bluetooth interfaced with Arduino board.

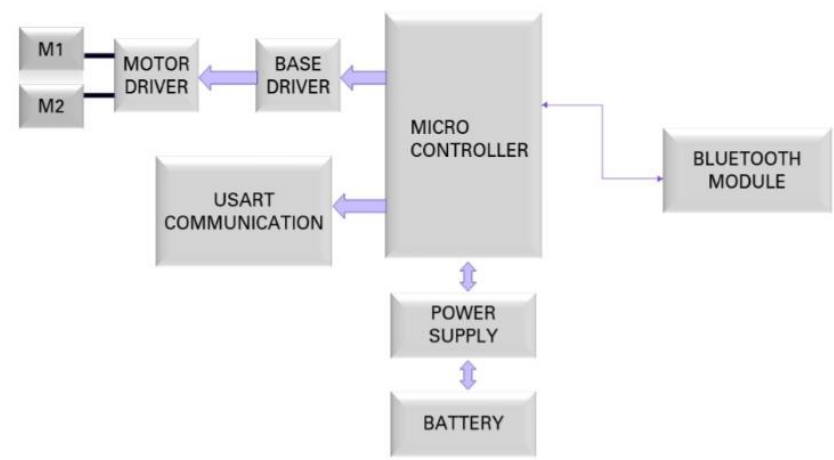

Fig. 11. Data Reception Block Diagram. 
Interfacing of the servo motor with motor driver and Arduino board is shown in Fig. 12. Whenever movement of the motor is required, signal is generated from the Arduino board and is fed to driver, driver amplifies the received signal that is of few $\mathrm{mA}$ and its amplified output is given to servo motor for movement of the robot in the desired direction.

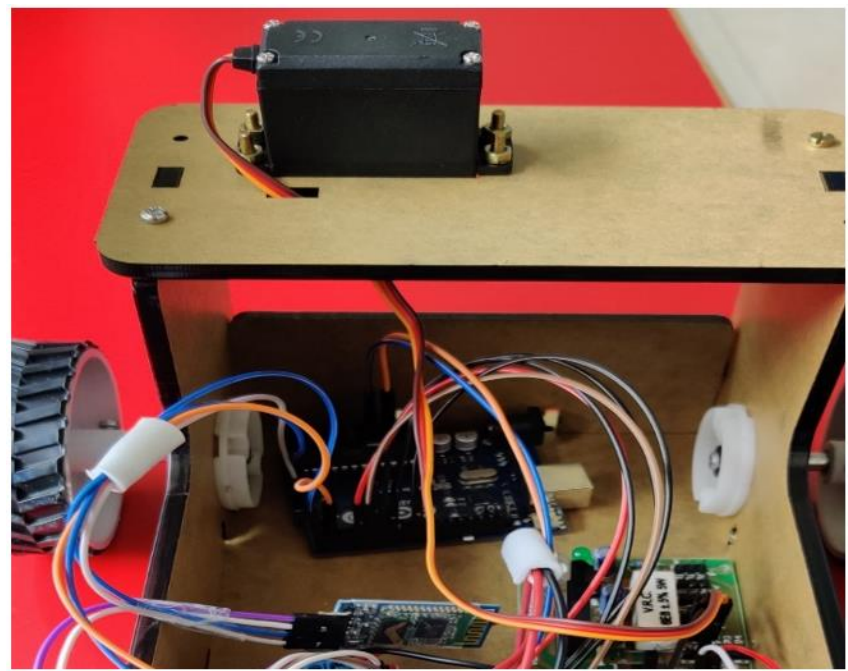

Fig. 12. Interfacing of Servo Motor with its Driver and Arduino Board.

The dispenser unit is connected on the upper part of the robot as depicted in Fig. 13. It is used to deliver medicine, blood sample, etc. in the hospital.

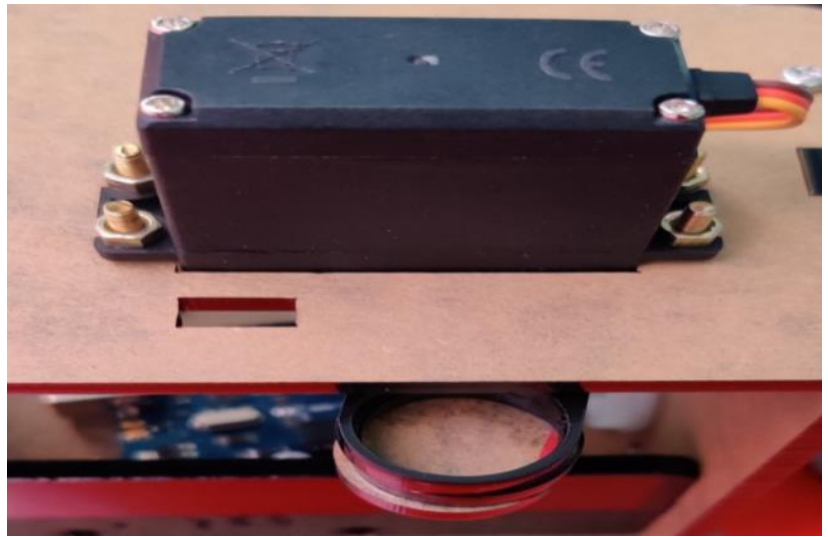

Fig. 13. Interfacing of Dispenser Unit.

Fig. 14 shows interfacing of power distribution board with battery and other related devices.

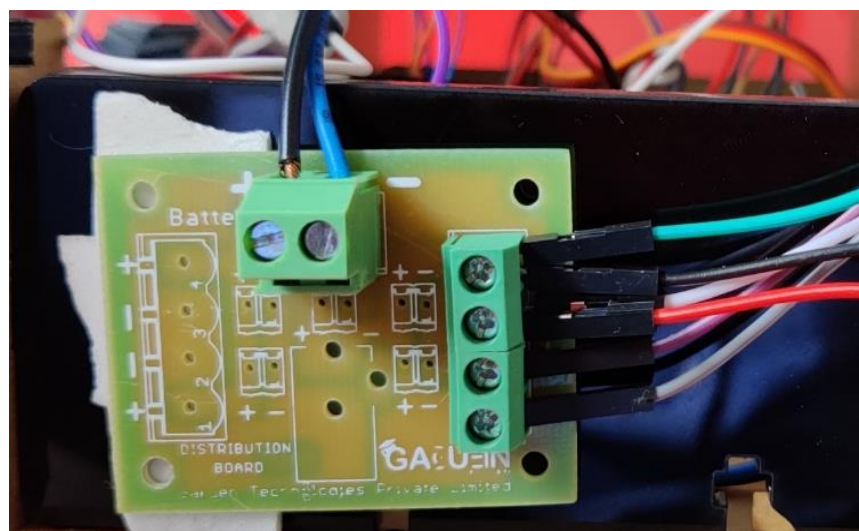

Fig. 14. Interfacing of Power Distribution Board.
Interfacing of Arduino with motor driver is depicted in Fig. 15. The main purpose of the driver is to amplify the received signal and drive servo motor, hence preventing Arduino board from being damaged from overload.

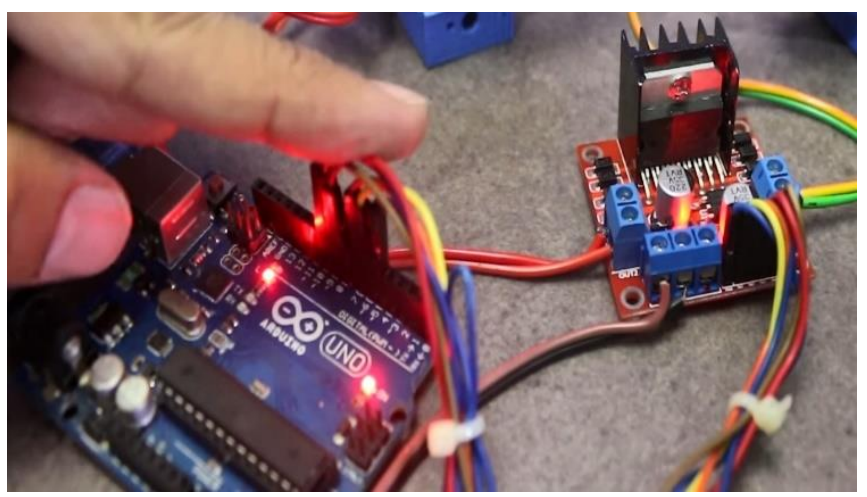

Fig. 15. Interfacing of Arduino with Motor Driver.

Fig. 16 shows how the DC motors that have been interfaced with the robot wheels to provide power for its movement.

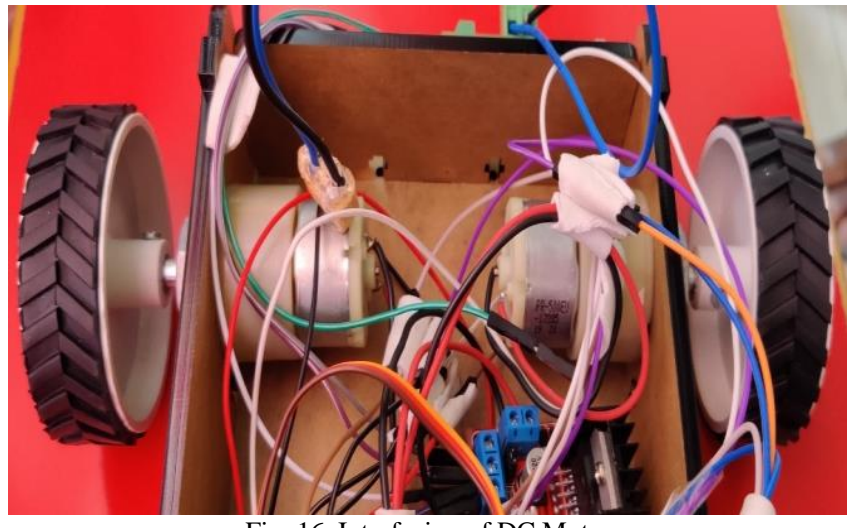

Fig. 16. Interfacing of DC Motor.

The overall interfacing of Arduino Board with other devices have been reflected in Fig. 17. UV-C LEDs have been mounted on the bottom of the robot to provide direct access of the surfaces to be disinfected. Similarly, the dispenser unit has been mounted on the top of the robot for efficient delivery of the desired medical items.

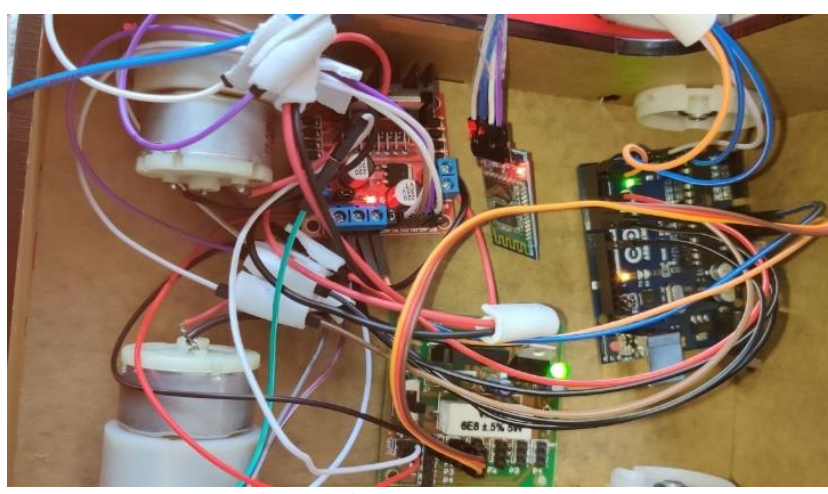

Fig. 17. Interfacing of Arduino Board with other Devices.

Fig. 18 shows the interfacing of final porotype module. It can be deployed on commercial basis if its size and component ratings are increased. 


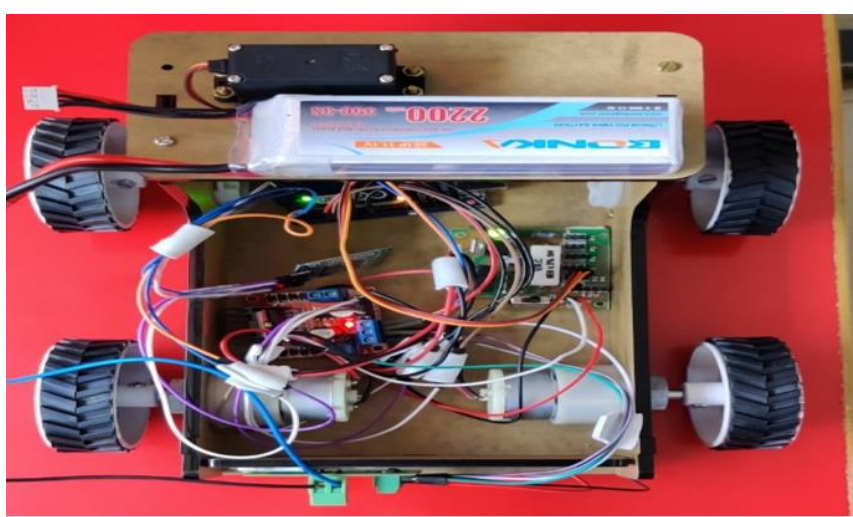

Fig. 18. Final Prototype Model.

But it would require further testing and certification from the competent agencies before commercial deployment in the healthcare sector.

\section{RESULTS AND DISCUSSIONS}

The disinfection capability of our automated designed robot using UV-C LEDs depends upon distance of object to be disinfected and length of time bacteria samples are exposed to the UV-C radiation. The measurement was carried out at 3 different distances: $0.5 \mathrm{~m}, 1.0 \mathrm{~m}$ and $1.5 \mathrm{~m}$ for 4 different time intervals: $5 \mathrm{~s}, 10 \mathrm{~s}, 15 \mathrm{~s}$, and $20 \mathrm{~s}$. With $265 \mathrm{~nm}$ wavelength of radiation, it is able kill $95.0 \%$ of bacteria within 20 seconds of exposure time when placed at a distance of 0.5 meter. Bacteria killing efficiency can further be enhanced without associated human risks if far UV-C rays with lower level of wavelength in the range of 207-222 nm is used, but use of far UV-C is still in its early stage and require further testing and investigations.

The designed robot has also been tested as dispenser for delivery of medicine and patient blood sample in the hospital. Its use has isolated affected patients from the hospital front line worker and also reduced the transportation time.

\section{CONCLUSION AND FUTURE WORK}

In order to prevent the spread of infection, and to overcome the difficulties and hardships caused by the virus during COVID-19 pandemic, healthcare sector has attracted service robot. Service robot has also been able to reduce direct contact of front-line healthcare staff by separating them from direct exposure to infection.

In the present work, we have designed a disinfection robot that radiates UV-C rays for UV sterilization of hospital floors. UVC disinfection is more effective than disinfection by hydrogen peroxide, and with other chemical base disinfectants like chlorine, chloramine, etc. With $265 \mathrm{~nm}$ wavelength of radiation, it is able kill $95.0 \%$ of bacteria within $20 \mathrm{~s}$ of exposure time when placed at a distance of 0.5 $\mathrm{m}$. Bacteria killing efficiency can further be enhanced without associated human risks if far UV-C rays with lower level of wavelength in the range of 207-222 $\mathrm{nm}$ is used, but use of far UV-C is still in its early stage.

Our robot has also been tested as dispenser in the hospital delivery system to deliver medicine to the patient and to carry blood samples from patient wards to the testing laboratories. Its use would not only increase logistics efficiency but would also avoid spread of hospital acquired infections (HAIs), healthcare associated infections, eliminate human error, and allow staff members to engage themselves in their higher priority works.

\section{REFERENCES}

[1] Yoram Gerchmana, Hadas Mamaneb, Nehemya Friedmanc, Micha Mandelboimc. UV-LED disinfection of Coronavirus: Wavelength effect. Journal of Photochemistry \& Photobiology, B: Biology, 2020; 212: 1-7.

[2] A.I. Silverman, A.B. Boehm, Systematic review and meta-analysis of the persistence and disinfection of human coronaviruses and their viral surrogates in water and wastewater. Environ. Sci. Technol. Lett., 2020.

[3] E. R. Blatchley III, B. Petri, W. Sunc. SARS-CoV-2 UV DoseResponse Behavior. International Ultraviolet Association (IUVA) White Paper, 2020.

[4] S.M. Duan, X.S. Zhao, R.F. Wen, J.J. Huang, G.H. Pi, S.X. Zhang, J Han, S.L. Bi, L. Ruan, X.P. Dong, Stability of SARS coronavirus in human specimens and environment and its sensitivity to heating and UV irradiation. Biomed. Environ. Sci, 2003:16 (3): 246-255.

[5] T.S. Fung, D.X. Liu, Post-translational modifications of coronavirus proteins: roles and function. Future Virol, 2018;13 (6): 405-430.

[6] Boyce J. M. Modern technologies for improving cleaning and disinfection of environmental surfaces in hospitals. Anti microb. Resist. Infect. Control 5:10, 2016.

[7] Casini, B., Tuvo, B., Cristina, M. L., Spagnolo, A. M., Totaro, M., Baggiani, A., et al, Evaluation of an ultraviolet c (UVC) light-emitting device for disinfection of high touch surfaces in hospital critical areas, Int. J. Environ. Res. Public Health 16, 2019.

[8] Elgujja, A., Altalhi, H., and Ezreqat, S. Review of the efficacy of ultraviolet c for surface decontamination, J. Nat. Sci. Med. 3, 2020, 812.

[9] Heßling, M., Hönes, K., Vatter, P., and Lingenfelder, C, Ultraviolet irradiation doses for coronavirus inactivation-review and analysis of coronavirus photo inactivation studies, GMS Hyg. Infect. Control 15:doc08, 2020.

[10] Miller, S., Linnes, J., and Luongo, J, Ultraviolet germicidal irradiation: future directions for air disinfection and building applications, Photochem. Photobiol. 2013; 89:777-781.

[11] D. A. Wolfe, Creating Digital Opportunity for Canada, Innovation Policy Lab at the Munk School of Global Affairs, University of Toronto | Brookfield Institute, Apr. 2018.

[12] D. A. Wolfe, A Digital Strategy for Canada: The Current Challenge Institute for Research on Public Policy, Feb. 2019; 25:20.

[13] UVD Robots. http://www.uvd-robots.com/home/ (accessed Sep. 02, 2020.

[14] Karabegovic, I, Dolecek, V, The role of service robots and robotic systems in the treatment of patients in medical institutions, In Advanced Technologies, Systems, and Applications; Springer: Berlin/Heidelberg, Germany, 2017:9-25.

[15] Vänni, K, Robot applications in communication. Smart Technological. Solution. Support Elder. Contin. Living Their Own Homes. Rep. Minist. Environ. 2017; 7: 44-51.

[16] UVD Robotics. Reduce Hospital Acquired Infections with the UV Disinfection Robot, (accessed on 21 October 2020).

[17] IEEE Spectrum. Diligent Robotics Bringing Autonomous Mobile Manipulation to Hospitals. 2018, (accessed on 18 January 2021).

[18] Aladin Begic, Application of Service Robots for Disinfection In Medical Institutions, Advanced Technologies, Systems, and Applications II. 28: 2018:1056-1065.

[19] Pacharawan Chanprakon, Tapparat Sae- Oung, Treesukon, An UltraViolet Sterilization Robot for Disinfection, 2019.

[20] Fletcher L, Noakes C, Beggs C, Sleigh P, The importance of bioaerosols in hospital infections and the potential for control using germicidal ultraviolet irradiation, 2004.

[21] J Holland, L Kingston, Cr McCarthy, Ee Armstrong, P O’Dwyer, Fi Merz and M McConnell, Service Robots in the Healthcare Sector MDPI Robotics 10, 47, 2021. 